J. Lake Sci. (湖泊科学), $2007, \mathbf{1 9}(4): 428-433$

http://www. jlakes.org. E-mail: jlakes@ niglas. ac.cn

(c) 2007 by Journal of Lake Sciences

\title{
天津市北塘水库水质咸化原因和防治对策
}

\author{
姜翠玲 ${ }^{1}$ ，裴海峰 ${ }^{2}$ \\ ( 1 : 河海大学水文水资源与水利工程科学国家重点实验室, 南京 210098) \\ $(2$ : 河海大学水资源环境学院, 南京 210098)
}

\begin{abstract}
摘 要: 为确定天津市北塘水库作为南水北调供水调节和事故备用水库的水质安全性,于 2005 年 $7-12$ 月,监测分析水 体、底泥和库周土壤中全盐量和 $\mathrm{Cl}^{-}$浓度的变化,研究水源补给、底泥释放、降雨蒸发和地下水水位变动等因素对水库水 质的影响。结果表明在目前蓄潮白新河水的条件下, 北塘水库水中的 $\mathrm{Cl}^{-}$浓度变化幅度为 $302-409 \mathrm{mg} / \mathrm{L}$, 超过饮用水水 源地的水质标准 ( GB3838 - 2002). 库区 $0-100 \mathrm{~cm}$ 底泥全盐量平均值为 $0.253 \%, \mathrm{Cl}^{-}$含量为 $0.048 \%$,分别是库周土壤 的 $1 / 8$ 和 $1 / 18.3$. 因此,蓄水造成水库底泥盐分的大量释放. 经计算, $\mathrm{Cl}^{-}$的平均释放强度为 $1.3 \mathrm{~g} /\left(\mathrm{m}^{2} \cdot \mathrm{d}\right)$. 南水北调 通水后,若水库保持在 $5.60 \mathrm{~m}$ 以上的运行水位, 底泥释放虽造成 $\mathrm{Cl}^{-}$浓度上升,但水质能达到供水水源地的标准. 水库周 边地下水的矿化度为 $59.63 \mathrm{~g} / \mathrm{L}, \mathrm{Cl}^{-}$浓度为 $26.17 \mathrm{~g} / \mathrm{L}$, 远高于水库水体的含盐量, 但只要在 $5.60 \mathrm{~m}$ 以上水位运行, 水库就 不会受到高矿化度地下水的补给影响. 因此,在合理调度的基础上, 北塘水库作为天津市南水北调供水调节和事故备用 水库是安全的.
\end{abstract}

关键词 : 北塘水库;水质咸化;矿化度;全盐量; $\mathrm{Cl}^{-}$;南水北调

\section{Reasons of water salinization and its prevention measures in Beitang Reservoir, Tianjin City}

\section{JIANG Cuiling ${ }^{1} \&$ PEI Haifeng ${ }^{2}$}

(1: State Key Laboratory of Hydrology-Water Resources and Hydraulic Engineering, Hohai University, Nanjing 210098, P. R. China)

(2:College of Water Resources and Environment, Hohai University, Nanjing 210098, P. R. China)

\begin{abstract}
Beitang Reservoir is planed as a regulating and accident standby reservoir in Tianjin city in the project of the South-to-North Water Diversion Engineering. To determine the security of water quality, total ion amount and $\mathrm{Cl}^{-}$in reservoir water and sediment and in soil around reservoir were detected from July to December of 2005. Effects of water supply, sediment release, rainfall, evaporation and groundwater level on water quality of reservoir were analyzed too. In this period, $\mathrm{Cl}^{-}$concentration varied from $302 \mathrm{mg} / \mathrm{L}$ to $409 \mathrm{mg} / \mathrm{L}$, which exceeded the maximum of drinking water source standard. The mean content of total ion amount in reservoir sediment from $0-100 \mathrm{~cm}$ was $0.253 \%$, and chloride content was $0.048 \%$, which account for only $1 / 8$ of total ion amount and $1 / 18.3$ of chloride content in soil around Beitang Reservoir. Therefore, water storage in reservoir led to release of salt from sediment. According to the $1.3 \mathrm{~g} / \mathrm{m}^{2}$ release intensity of chloride every day, water quality of Beitang Reservoir can satisfy to the standard of drinking water source when water level keeps above $5.6 \mathrm{~m}$. Total ion amount and $\mathrm{Cl}^{-}$concentration in groundwater around reservoir were $59.63 \mathrm{~g} / \mathrm{L}$ and $26.17 \mathrm{~g} / \mathrm{L}$ respectively, which were much higher than that in reservoir water. As long as the running water level of reservoir keeps above $5.6 \mathrm{~m}$, the reservoir would be not affected by groundwater. By the reasonable control, Beitang Reservoir is feasible to work as a regulating and accident standby reservoir in Tianjin city in the near future.
\end{abstract}

Keywords: Beitang Reservoir; water salinization; total ion amount; $\mathrm{Cl}^{-}$; South-to-North Water Diversion Engineering Project

* 天津市南水北调工程建设委员会办公室资助. 2006-06-20 收稿; 2006-09-27 收修改稿. 姜翠玲, 女, 1966 年 生,博士,教授;E-mail:cljianghhu@ 163.com. 
北塘水库位于天津市塘沽区北塘镇北约 $2 \mathrm{~km}$ 处, 北纬 $39^{\circ} 06^{\prime}-39^{\circ} 08^{\prime}$ 和东经 $117^{\circ} 38^{\prime}-117^{\circ} 41^{\prime}$ 之间, 地处渤海沿岸, 北依永定新河, 是一座平原型水库, 由海浸和现代河流冲积而成, 地貌特征为泻湖洼地, 地势 低平, 土壤以灰黑色粘性土为主, 渗透性较差. 北塘水库于 1974 年经连续围堤封闭而成, 库区占地面积 $7.43 \mathrm{~km}^{2}$, 地面平均高程 $2.3 \mathrm{~m}, 2002$ 年增容加固后其总库容达到 $3977 \times 10^{4} \mathrm{~m}^{3}$. 设计水位 $7.00 \mathrm{~m}$, 死水位 $2.80 \mathrm{~m}$, 北塘水库原有功能以灌溉和水产养殖为主, 但也曾于 20 世纪 80 年代中期至 90 年代末多年次给塘 沽市区应急输水. 现状蓄水水源主要是跨永定新河抢蓄潮白新河汛期水, 库水矿化度较高, 大多情况下达 不到生活饮用水水源地标准 (《地表水环境质量标准》GB3838-2002).

水是城市发展的命脉, 滨海新区作为天津市的重要经济区域,水资源短缺已成为制约本地区可持续发 展的主要因素之一. 为合理利用南水北调中线水源, 根据天津市城市发展规划, 拟将北塘水库作为滨海地 区城市供水调节及事故备用水库, 以实现引滦水和引江水的联合调度和应急切换, 提高城市供水的安全保 证率. 但是水库距离渤海湾较近,水库蓄水后是否存在水质咸化问题, 是关系到滨海地区能否正常供水的 关键. 位于同一区域的北大港水库水质就存在着咸化问题 ${ }^{[1-4]}$. 赵文玉等通过模拟实验发现北大港水库库 底土壤盐化程度高 (含盐量 $0.2 \%-1.5 \%$ ), 盐碱土向水体中的传质作用是蓄存引黄水后水质咸化的主要 原因, 另外蒸发浓缩和风的扰动加快了水库的咸化速度 ${ }^{[3]}$. 近些年, 有很多学者研究了滨海地区水库水质 的咸化问题, 朱江平 ${ }^{[5]}$ 认为海水的渗人是宁海县胡陈港水库水质咸化的主要原因; 高增文等 ${ }^{[6]}$ 通过实验模 拟发现底泥盐分的释放通量以负的幂指数形式下降; 宋金明 ${ }^{[7]}$ 采用 Fick 定律,对中国近海沉积物 - 海水界 面物质的扩散通量进行了分析计算; Portielje 和 Lijklema ${ }^{[8]}$ 对荷兰 Veluwe 湖的沉积物 - 水之间物质交换进 行了室内试验和模型分析; French 和 Harley 等 ${ }^{[9]}$ 利用淡水人流与库内底层水体出流相等的模式预测了新 加坡 Sungei Seletar 水库内水体盐分的变化趋势; 余靕 ${ }^{[10]}$ 和 Mao X Z 等 ${ }^{[11-13]}$ 研究并预测了浙江省漩门二期 堵港蓄淡水库在运行时库内水体淡化的过程及其效果.

虽然北塘水库与北大港水库所处的地理位置和气候条件相近, 但两者在地质条件上相差很大, 北大港 水库一带属于受海水进退影响的泻湖相沉积, 历史上大陆水作用特征不明显. 而北塘水库是大陆水和海水 同时作用形成的陆源海相层, 积盐程度小于北大港水库. 为了解北塘水库水质咸化的主要原因, 预测南水 北调通水后,水库在运行过程中的水质安全性,2005 年 7 月 -12 月,对水库汛期蓄水后水质变化及底泥、周 边土壤和地下水的含盐量水平进行了监测和分析, 提出了水质咸化的风险和防治对策.

\section{1 野外监测采样、实验方法}

\section{1 野外监测}

1.1 .1 水质监测 2005 年 7 月北塘水库三次引蓄潮白新河水. 第一次:7 月 7 日 -10 日,引水总量 $150 \times 10^{4}$ $\mathrm{m}^{3}$. 第二次:7 月 15 日 -22 日,引水总量 $642 \times 10^{4} \mathrm{~m}^{3}$. 第三次: 7 月 23 日 -27 日,引水总量 $212 \times 10^{4} \mathrm{~m}^{3}$. 为了解潮白新河水质变动对水库水质的影响, 在潮白新河的引水口处布设 1 个监测点, 引水期间每日监测 河水矿化度、 $\mathrm{Cl}^{-}$浓度. 在北塘水库库区采用网格布点法布设 9 条水质监测垂线 (图 1 ), 每条垂线在水面下 $0.5 \mathrm{~m}$ 、库底向上 $0.5 \mathrm{~m}$ 、中间深度处各布设一个监测点. 在 7 月调水期间,每日监测水库水中矿化度、 $\mathrm{Cl}^{-}$浓 度, 调水前及调水后 $(8-11$ 月), 每隔 $1-2$ 周监测 1 次盐分浓度的变化. 在水库周边布设四个地下水勘测 孔, 孔深为 $3.75-5.8 \mathrm{~m} .7-12$ 月,每月监测水位和地下水中的全盐量、 $\mathrm{Cl}^{-}$浓度.

1.1 .2 水库底泥和周边土壤监测 2005 年 7 月 8 日 - 16 日,用网格布点法在水库中布设 16 个底泥取样 点, 并在库外布设 2 个土壤取样点, GW2 和 GW4 (图 1, 形成地下水勘测孔前为土壤取样点). 用半圆形取样 器, 取深度为 $0-100 \mathrm{~cm}$ 的水库底泥样品和周边土壤样品, 现场将原状样品按 $0-5 \mathrm{~cm} 、 5-10 \mathrm{~cm} 、 10-20$ $\mathrm{cm} 、 20-40 \mathrm{~cm} 、 40-60 \mathrm{~cm} 、 60-80 \mathrm{~cm} 、 80-100 \mathrm{~cm}$ 七层分装, 运回实验室分析各层中的全盐量和氯化物 含量.

\section{2 实验方法}

水体中氯离子的测定用硝酸盐滴定法 (GB11896-89), 矿化度的测定用重量法(SL79-1994).

底泥和土壤样品经风干、磨细过篮后, 用去离子水配置水土比为 5:1 的浸出液, 取清液进行测定. 氯离 子含量用硝酸盐滴定法测定, 全盐量用重量法测定. 


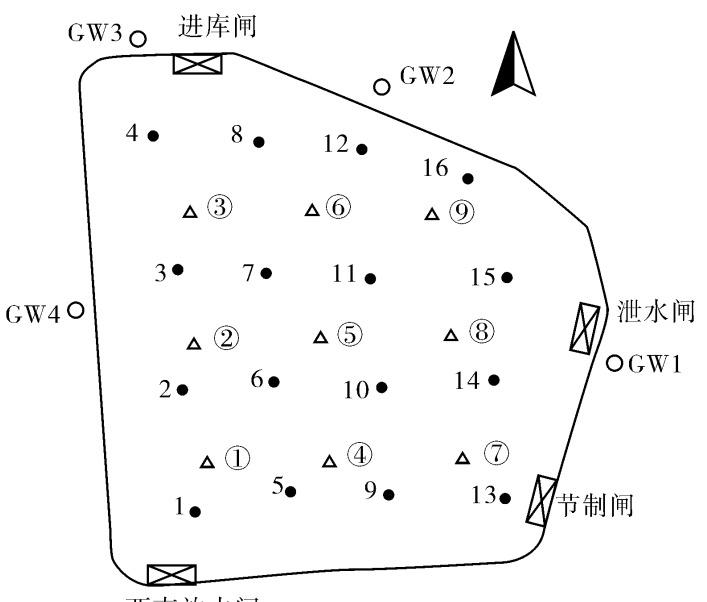

西南放水闸

$\triangle:$ 水质监测点; $\bullet$ : 底泥取样点;

$\mathrm{GW} 1-\mathrm{GW} 4$ : 地下水监测点

图 1 北塘水库各监测点位置图

Fig. 1 Water sampling stations in Beitang Reservoir

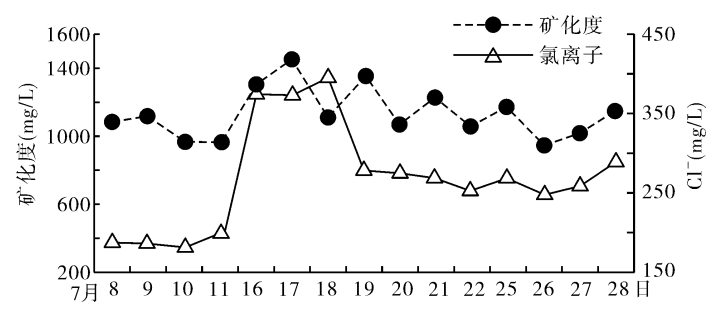

图 2 引水期间潮白新河矿化度和 $\mathrm{Cl}^{-}$浓度变化

Fig. 2 Variation of total ion amount and $\mathrm{Cl}^{-}$concentrations in Caobai New River during water transfer period

和水库的库底面积 $\left(6.72 \mathrm{~km}^{2}\right)$, 计算底泥氯化物的释放强度为 $1.3 \mathrm{~g} /\left(\mathrm{m}^{2} \cdot \mathrm{d}\right)$.

表 12005 年 $7-11$ 月北塘水库的气象水文和水质条件

Tab. 1 Weather, hydrology and water quality conditions in Beitang Reservoir from July to November of 2005

\begin{tabular}{ccccccc}
\hline 月份 & $\begin{array}{c}\text { 降雨量 } \\
(\mathrm{mm})\end{array}$ & $\begin{array}{c}\text { 蒸发量 } \\
(\mathrm{mm})\end{array}$ & $\begin{array}{c}\text { 水位 } \\
(\mathrm{m})\end{array}$ & $\begin{array}{c}\text { 库容 } \\
\left(\times 10^{4} \mathrm{~m}^{3}\right)\end{array}$ & $\begin{array}{c}\mathrm{Cl}^{-} \text {平均浓度 } \\
(\mathrm{mg} / \mathrm{L})\end{array}$ & $\begin{array}{c}\text { 氯化物总量 } \\
(\mathrm{t})\end{array}$ \\
\hline 7 & 66.6 & 136.6 & 6.45 & 3580 & 355 & 12707 \\
8 & 148.7 & 96.4 & 7.07 & 3977 & 338 & 13457 \\
9 & 44.8 & 98.9 & 7.00 & 3977 & 339 & 13497 \\
10 & 18.6 & 83.0 & 6.92 & 3919 & 345 & 13502 \\
11 & 0.0 & 87.6 & 6.83 & 3919 & 348 & 13657 \\
\hline
\end{tabular}

\section{2 水库底泥盐分的水平与垂向分布}

根据我国第二次土壤普查的土种划分标准 ${ }^{[16]}$, 滨海地区按 $1 \mathrm{~m}$ 土体盐分含量的百分比可划分为: 非盐 
化土、轻盐化土、中盐化土、重盐化土和滨海盐土五大类 (表 2).

表 2 底泥盐化程度分类表

Tab. 2 Classification of sediment salted degree in Beitang Reservoir

\begin{tabular}{cccccc}
\hline 盐化程度 & 非盐化土 & 轻盐化土 & 中盐化土 & 重盐化土 & 滨海盐土 \\
\hline 盐分含量 $(\%)$ & $<0.1$ & $0.1-0.2$ & $0.2-0.4$ & $0.4-0.6$ & $>0.6$ \\
\hline
\end{tabular}

对 16 个点的底泥样品进行分析, 发现氯化物和全盐量在各监测点的分布是不均匀的. 在 $1 \mathrm{~m}$ 深度范围 内底泥全盐量的平均浓度变化于 $0.030 \%-0.458 \%$ 之间, 属非盐化和重盐化土,氯化物含量范围为 $0.009 \%$ $-0.141 \%$. 水库四周底泥盐分含量高, 库中部和北部的进库闸处盐分含量低. 由于水库是由泻湖洼地围堤 而成, 中间地势低,易蓄水,底泥中盐分释放和淋溶的机率高. 而水库四周地势高, 在干旱年份会裸露出来, 加上地表蒸发的影响, 盐分含量高 ${ }^{[17]}$. 水库建成后, 汛期多年次引低矿化度的潮白新河水, 对进库闸附近 区域不断的冲洗和淋滤,使目前北部底泥盐分含量低.

$0-100 \mathrm{~cm}$ 底泥中的氯化物和全盐量基本上都随 深度增加呈上升趋势 ( 图 4), 表明上层底泥由于长期浸 泡, 大量盐分释放出来, 使上层底泥中的含量不断下 降. 另外, 在上覆水水压力的作用下, 底泥中的盐分也 能向下渗漏, 造成氯化物和全盐量随深度增加而含量 上升. 因此, 水库在蓄低矿化度水的条件下, 释放和下 渗将使底泥中的盐分含量不断下降, 尤其使表层底泥 中的含盐量水平显著降低.

\section{3 水库底泥与周边土壤含盐量水平的对比}

北塘水库是 1974 年在原洼淀通过连续围堤封闭 而成, 为分析长期蓄水、换水对库区底泥盐分释放的影 响, 2005 年 7 月, 取北塘水库库周 $0-100 \mathrm{~cm}$ 土壤, 对比 分析了水库底泥与库周土壤各层中全盐量和氯化物含 量的差别. 图 4 表示 8 个底泥取样点和 2 个库周土壤 取样点的全盐量和氯化物的垂向分布, 库周土壤属滨 海盐化土, 含盐量高, 从表层至 $100 \mathrm{~cm}$ 深度, 全盐量平 均值为 $2.0 \%$, 含量范围为 $1.03 \%-3.34 \%$; 氯化物的 平均值为 $0.88 \%$, 含量范围为 $0.48 \%-1.46 \%$. 相比 之下, 经 20 多年的蓄水浸泡, 北塘水库库区底泥含盐 量水平已显著下降, 表层至 $100 \mathrm{~cm}$ 深度底泥全盐量的 平均值为 $0.253 \%$, 含量范围为 $0.030 \%-0.458 \%$; 氯 化物的平均值为 $0.048 \%$, 含量范围为 $0.009 \%-$ $0.141 \%$, 分别是库周土壤全盐量和氯化物的 $1 / 8$ 和 $1 /$ 18.3. 因此, 低矿化度的蓄水会促使水库底泥盐分的释 放, 经常蓄水、换水将使底泥盐分浓度不断下降. 南水 北调通水后, 由于丹江口水库水中的 $\mathrm{Cl}^{-}$浓度仅为 20 $-27 \mathrm{mg} / \mathrm{L}$, 远低于目前北塘水库的 $302-409 \mathrm{mg} / \mathrm{L}$, 因
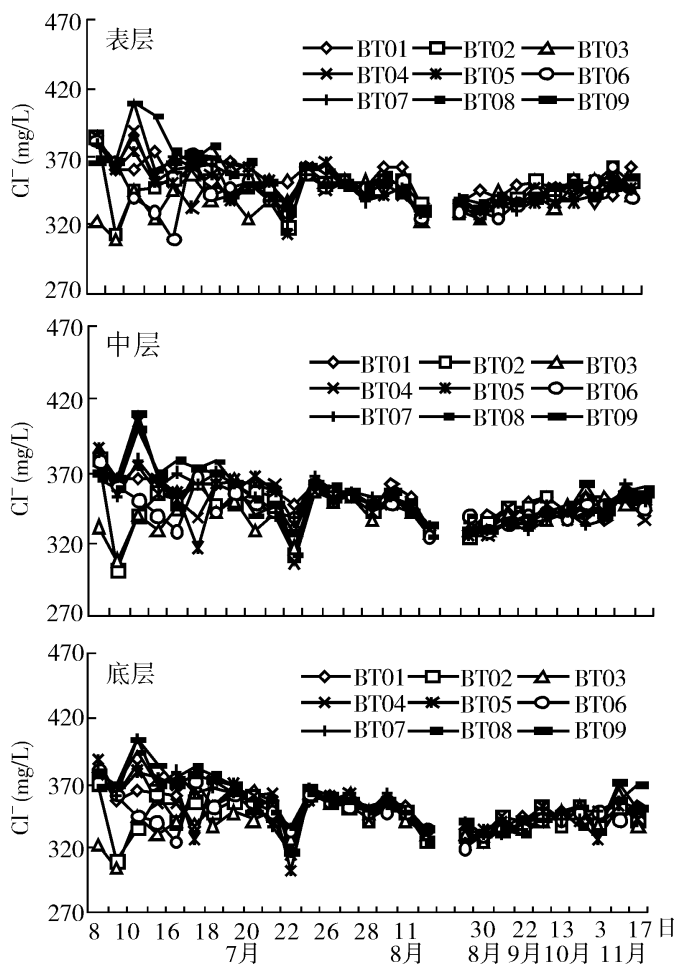

图 32005 年 7-11 月北塘水库 $\mathrm{Cl}^{-}$在表、中、 低三层的浓度变化 (BT - 北塘水库水质监测点)

Fig. 3 Variations of $\mathrm{Cl}^{-}$concentration in surface, middle and bottom layers of Beitang Reservoir water from July to November of 2005 此, 在蓄南水北调中线水的初期, 底泥盐分释放强度较大, 会造成库水盐分含量的上升, 但随时间推移, 不断 的蓄水换水会使库水的盐分浓度越来越低,最后趋于平稳.

\section{4 地下水补给的可能性分析}

2005 年 $7-12$ 月库周四个监测孔地下水的矿化度为 $18.36-98.57 \mathrm{~g} / \mathrm{L}$, 平均值为 $59.63 \mathrm{~g} / \mathrm{L}^{-} \mathrm{Cl}^{-}$浓度 

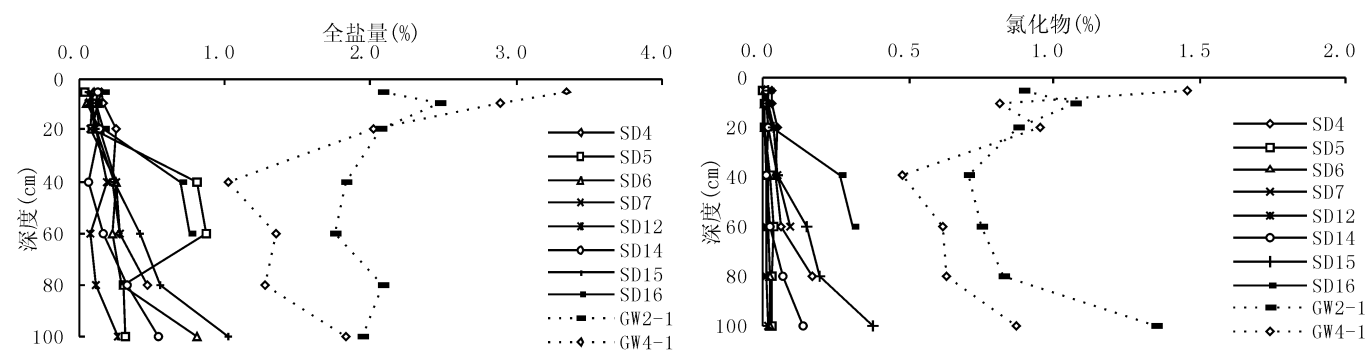

图 4 库区底泥和库周土壤全盐量和氯化物的垂向分布 (SD : 库区底泥监测点; $\mathrm{GW}$ : 库周土壤监测点)

Fig. 4 Vertical distribution of total ion amount and chloride in reservoir sediment and in soil outside reservoir

为 $7.99-41.54 \mathrm{~g} / \mathrm{L}$, 平均 $26.17 \mathrm{~g} / \mathrm{L}$, 远高于北塘水库的含盐量水平. 因此, 若水库受到地下水的补给, 会造 成含盐量的急剧上升. 北塘水库设计水位 $7.00 \mathrm{~m}$, 死水位 $2.80 \mathrm{~m} .2005$ 年 $7-12$ 月份水库附近地下水位最 高 $4.74 \mathrm{~m}$, 水库附近地面高程最高 $5.52 \mathrm{~m}$. 虽然不能确定库周边历年地下水的最高水位,但地下水水位不 会超过水库附近地面最高高程 $(5.52 \mathrm{~m})$, 可以认为, 当水库保持在 $5.60 \mathrm{~m}$ 以上的水位运行, 就等于控制了 地下水与库水位的水位差, 也就控制了高矿化度地下水直接补给库水的可能性. 理论上, 高矿化度地下水 可以通过界面的盐度梯度向上扩散,使底泥和库水含盐量增加 ${ }^{[18-20]}$, 但从图 4 的实验结果看, 库区底泥盐 分含量明显低于不蓄水的周边土壤，其盐分的垂直分布梯度也与土壤不同，表层底泥盐分含量最低. 因此, 在上覆水压力、库水渗漏及粘性土底泥隔离等因素的综合作用下,高矿化度地下水向上扩散补给库水的可 能性很小. 从水质安全的角度考虑, 将 $5.6 \mathrm{~m}$ 水位作为北塘水库运行的最低设计水位, 可以避免水质咸化 的风险.

\section{3 北塘水库水质咸化的防治对策}

(1) 北塘水库库周土壤的全盐量和氯化物含量分别是库区底泥的 8 倍和 18.3 倍,低矿化度的蓄水造 成水库底泥盐分的释放,经常蓄水、换水会使底泥盐分浓度下降. 建议在南水北调通水之前,每年汛期蓄低 矿化度的潮白新河水,促进底泥盐分释放,减轻底泥污染负荷.

(2) 若水库在设计低水位 $5.60 \mathrm{~m}$ 和设计高水位 $7.00 \mathrm{~m}$ 之间运行,因水位高于周边地面高程 $(5.52 \mathrm{~m})$, 高于可能出现的高地下水水位,水库周边高矿化度的地下水不会补给水库,而造成库水的污染.

(3) 按目前北塘水库 $0-100 \mathrm{~cm}$ 底泥中氯化物的平均含量 $0.048 \%$ 、实测底泥容重 $1.27 \mathrm{~g} / \mathrm{cm}^{3}$ 计算, 若 所有的氯离子全部释放出来 (假定的最不利条件), 则南水北调中线通水后 (蓄丹江口水库水, $\mathrm{Cl}^{-}$最高浓度 $27 \mathrm{mg} / \mathrm{L}$ ), 水库在高水位 $\left(7.0 \mathrm{~m}\right.$ ) 条件下运行 (容积为 $3977 \times 10^{4} \mathrm{~m}^{3}$ ), 水库水中的 $\mathrm{Cl}^{-}$浓度将达到 130.82 $\mathrm{mg} / \mathrm{L}$, 符合饮用水水源地水质标准 $\left(\leqslant 250 \mathrm{mg} / \mathrm{L}\right.$ ). 即使低水位 $\left(5.6 \mathrm{~m}\right.$ ) 运行 (容积为 $3002 \times 10^{4} \mathrm{~m}^{3}$ ), 南水 北调中线通水后, 北塘水库 $\mathrm{Cl}^{-}$浓度将为 $137.53 \mathrm{mg} / \mathrm{L}$, 仍符合饮用水水源地水质标准. 但若到死水位,水库 容积为 $1019 \times 10^{4} \mathrm{~m}^{3}$, 即使不考虑地下水的补给, 底泥中氯离子全部释放将使水库浓度达到 $405.18 \mathrm{mg} / \mathrm{L}$. 因此,水库在设计低水位 $(5.6 \mathrm{~m})$ 以上运行, 底泥释放出来的氯离子对水库水质影响小, 北塘水库作为南水 北调调节及事故备用水库是安全的.

\section{4 参考文献}

[1] 张宇龙,王启山,贺兰畹等. 北大港水库调蓄 “引江水” 水质变化. 城市环境与城市生态, 2005,18 (2): $24-26$.

[2] 赵文玉,王启山,伍 婷等. 天津滨海地区水库水质咸化问题及机理分析. 海河水利, 2006, (3):33 -35 .

[3] 赵文玉, 王启山,刘 军等. 引黄水在北大港水库蓄存期水质咸化的研究. 水科学进展, 2005,16(6): $763-766$. 
[4] 赵文玉, 王启山, 吴国平等. “引黄水” 在北大港水库蓄存期水质咸化机理分析及防治措施. 南水北调 与水利科技, $2004,2(6): 24-26$.

[5] 朱江平. 胡陈港水库水质咸化原因分析及治理对策. 浙江水利科技,2002,(4):50-51.

[6] 高增文,郑西来, 吴俊文. 海湾水库蓄水初期底质与淡水盐分交换的试验研究. 水科学进展, 2006,17 (2) $: 170-175$.

[7] 宋金明. 中国近海沉积物 - 海水界面化学. 北京:海洋出版社, 1997:56-68.

[8] Portielje R, Lijklema L. Estimation of sediment-water exchange of solutes in Lake Veluwe, the Netherlands. Water Research, 1999, 33(1):279-285.

[9] French J A, Harley B M, Neysadurai A. Desalination of an impounded estuary. Environmental Engineering, Proceedings of the 1985 Specialty Conference. New York: ASCE, $1985: 91-97$.

[10] 余 壁. 浙江海涂水库水质淡化的分析与预测. 环境污染与防治, 1996,18(2):27-29.

[11] Mao X Z, Chen F Y, Yu Q W. 3-D stratification modeling for water desalination in a polder reservoir. Proceedings of the International Conference on Estuaries and Coasts. Hangzhou: Zhejiang University Press, $2003: 822-828$.

[12] 毛献忠, 朱小敖, 陈甫源等. 沿海堵港蓄淡水库加快水体淡化措施的研究. 水科学进展, 2005, 16 (6): $773-776$.

[13] 毛献忠,陈甫源, 余祈文等. 堵港蓄淡水库水体淡化预测研究. 水利学报, 2004,(7):79-84.

[14] 潘桂娥,黄罗春,金利军. 沿海滩涂水库蓄淡技术研究. 水利规划与设计,2004,(2):51-55.

[15] 杽自立,马英杰,张 惠等. 塔里木河水质盐化及改善途径. 水科学进展, 2002,13(6):719-725.

[16] 章士炎. 试论土种的划分和命名.土壤肥料,1994,(1):1-4.

[17] 李海妮,陈飞星.海涂水库水体淡化影响因素分析. 东北水利水电, 2005,23(255):42-44.

[18] 张永祥,薛禹群,陈鸿汉. 潍坊咸 - 卤水人侵引起的地下水化学成分变化及其对环境的影响. 环境科学 学报, $1997, \mathbf{1 7}(3): 295-301$.

[19] 君泽生, 林文盘, 杨小军. 海水人侵研究的现状与问题. 地理研究, 1991,10(3):78-86.

[20] 张 利. 咸水利用若干问题的探讨. 自然资源学报,1994,9(4)375-378. 